\author{
Andrea Szalavetz ${ }^{1}$ \\ Institute of World Economics MTA KRTK, \\ Hungarian Academy of Sciences
}

\title{
A Dynamic Capabilities Perspective of High-Growth Firms: Organizational Aspects
}

„... while dynamic capabilities are certainly idiosyncratic in their details [...] specific dynamic capabilities also exhibit common features that are associated with effective processes across firms." [Eisenhardt-Martin, 2000, p. 1108.]

\begin{abstract}
Drawing on interviews conducted at five Hungarian high-growth firms (HGFs), this paper discusses how dynamic capabilities shape the outcome of HGFs' efforts to meet the managerial challenges posed by rapid growth. HGFs are investigated in the context of a relatively under-researched country: Hungary. The research demonstrates that dynamic capabilities have strong explanatory power for the surveyed companies' achievements, in a similar manner to what is established in the literature on HGFs in advanced economies.

The micro-mechanisms of DC' deployment is explored by investigating the organizational solutions implemented at the surveyed firms in response to emerging growth-related problems. These responses were found to be similar across the sample. The recurrent growth-related reconfiguration of organizational structures and introduction of various organizational innovations were the result of systematically developed DC and non-abating organizational learning.
\end{abstract}

Keywords: high-growth firms, dynamic capabilities, organizational innovations, organizational learning, Hungary

JEL: L22, L25, L26 


\section{Introduction}

Ever since the contribution of high-growth firms (HGFs) to job creation, aggregate economic performance and productivity growth became obvious, and their above average innovativeness and internationalization potential recognized [classical references include Birch, 1979; Birch-Medoff, 1994; Davidsson, 1991; Storey, 1994; see also literature reviews by Ács, 2011; Coad et al., 2014; Delmar et al., 2003; Henreksson-Johansson, 2010], a wealth of studies have set up theoretical frameworks to identify the factors that account for HGFs' performance.

While the classical strand within the scholarship on HGFs has unanimously demonstrated their heterogeneous nature (HGFs are not concentrated in high-technology sectors, nor are they necessarily new or small firms - see reviews by Coad et al., 2014; Delmar et al., 2003; Henreksson-Johansson, 2010], management and entrepreneurship scholars have highlighted the homogeneity of factors that explain high growth performance [Chan et al. 2006; Colombelli et al., 2014; Parker et al., 2010; Smallbone et al., 1995; Sadler-Smith et al., 2003]. These latter scholars posit that behavioral features, such as founder profiles and entrepreneurial vision, management style and managerial skills need to be examined in the context that these attributes are leveraged: the mechanism by which entrepreneurs overcome the recurring managerial challenges. Success can be explained with the features of the entrepreneurial process of identifying, evaluating and exploiting business opportunities, rather than with the features of the entrepreneurs.

The challenges entrepreneurs face, and the attributes needed to overcome them, are quite similar in rapid growth periods. Scrutinized from the point of view how the entrepreneurial process is managed, HGFs are similar. HGFs resemble each other in terms of the dynamic and flexible character of their management strategy, and their outstanding organizational learning and adaptation capability [Barbero et al., 2011; Chan et al., 2006].

In short, management scholars tend to identify similarities rather than differences in the HGF-ecosystem: they point to various dynamic capabilities as key, cross-cutting explanatory factors of outstanding performance.

This paper applies the dynamic capabilities framework for the analysis of a subset of HGFs: technology-oriented, relatively young, small and medium-sized enterprises (SMEs).

The central research question is how dynamic capabilities (DC) manifest themselves while HGFs strive to meet the managerial challenges posed by rapid growth. This issue, i.e. the micro-mechanisms of firms' deploying their DC, is relatively under-investigated: most papers are conceptual (they are limited to a theoretical discussion of DC).

Accordingly, the aim of this paper is to test theory through case study-based research. Our analysis is based on interviews with the owners \& founders and/or top managers of five Hungarian HGFs, selected from the author's database of successful Hungarian SMEs. Case studies allow for a deep and detailed insight in the qualitative issues our investigation 
focuses on. We explore the problems that emerged in the course of rapid growth periods and the organizational solutions proposed as a response to these problems.

Although we focus here on proposed organizational solutions, and argue that effective organizational responses reflect DC, this is not intended to suggest that organizational transformations are the only, or most important, manifestations of DC. Organizational changes represent one element in the complex process of firms' reconfiguring internal and integrating external resources. The accumulation and the deployment of DC is an incessant process: it is present, albeit with varying accents and manifestations, throughout a firm's life cycle. Organizational changes are the subject of our research because practically all corporate initiatives and newly-decided strategic directions have organizational implications as well. Consequently, investigating the deployment of DC through the prism of organizational changes at the surveyed HGFs offers valuable insights for inductive reasoning.

Based on prior literature, next section defines DC and describes the context of Hungarian HGFs. Following section presents our research method and introduces the sample companies, and the next one reviews and discusses the research results. Last Section provides further discussion, our conclusion, and some of the limitations of the research.

\section{Definition and Context}

Responding to Terjesen et al's [2013] call to extend the current dominant theoretical perspectives of entrepreneurship research (e.g. institutions, culture, resource-based view, transaction cost economics) and integrate theories from management and international business scholarship, this paper draws on the concept of DC [Eisenhardt-Martin, 2000; Teece et al. 1997] when analyzing the means of organizational transformation during a rapid growth process.

From a wealth of partially overlapping definitions of DC [see reviews by Hsu-Wang, 2012; Zahra et al., 2006] we formulate ours as capabilities to build, release, and reconfigure a firm's internal resources and integrate external ones, in response to changes in the external and internal business environment. This definition distinguishes DC from a firm's substantive (operational) capabilities needed to perform basic functional firm activities: DC change, extend or reconfigure existing substantive capabilities [Winter, 2003]. DC are accumulated through deliberate organizational learning [Eisenhardt-Martin, 2000; Zollo-Winter, 2002]. According to Zahra et al's insightful explanation "managers [...] do not, and probably should not, create 'once-and-for-all' solutions or routines for their operations but continually re-configure or revise the capabilities they have developed" [2006, p. 920-21].

The strong relationship between DC and entrepreneurship theories is evident in the light of Teece's [2007] extended definition of DC. Teece disaggregates DC into "the 
capacity (1) to sense and shape opportunities and threats, (2) to seize opportunities, and (3) to maintain competitiveness through enhancing, combining, and, when necessary, reconfiguring the business enterprise's tangible and intangible assets" [p. 1319].

Development of DC is accompanied and engendered by the accumulation of complementary assets [Teece, 1986] and by organizational changes. In a reciprocal relation, complementary assets assist managers' integration, building and reconfiguration of internal and external competencies. Conversely, DC are indispensable for effective complementary asset accumulation: for identifying, building and/or accessing the resources that will be necessary to capture the benefits of a firm-specific strategy, technology, or innovation. In a similar vein, the development of specific organizational forms, such as flexible organisations featuring a high degree of delegation, make it easier for firms to generate innovations and access external knowledge: an important dynamic capability [Foss et al., 2011]. Conversely, DC are necessary to ensure a continuous alignment between a firm's modes of organizing and its changing strategic needs.

Another line of research related to our investigations concerns HGFs in general and managerial challenges associated with high growth in particular. The experiences of the highest-performing segment of the entrepreneurial ecosystem constitute a field of increasing scholarly attention within the entrepreneurship literature [Coad et al., 2014; Wennberg, 2013]. Although, as pointed out by Wennberg [2013], most studies in this field are macro-oriented, and investigate the role of HGFs for job creation, industry dynamics, economic growth and innovation [see e.g. Ács, 2011], the scholarship encompassing contributions that adopt a managerial approach when investigating HGFs is also reaching a mature stage.

Contributions to this latter strand can be summarized as being concerned with why and how HGFs grow. The first question addresses - among others - the features and behavior of HGFs and of their founders [e.g. Sadler-Smith et al., 2003; St-Jean et al., 2008].The second investigates HGFs' strategy; for example, how technological and market knowledge is built up, configured and reconfigured in the growth process, [e.g. Deligianni et al., 2014].

A research question frequently addressed by strategic management scholars concerns the ways HGFs overcome challenges that emerge during rapid growth [Agarwal-Helfat, 2009; Hambrick-Crozier, 1986; Mueller et al., 2012; Wasserman, 2008]. The consensus in the literature is that new and additional managerial capabilities become indispensable when as firms grow. As organizations become more complex, they need to undergo multiple renewal processes (managerial practices need to change and organizational attributes refreshed, replaced and/or reconfigured).

HGFs became the subject of scholarly scrutiny relatively recently in Hungary. For nearly two decades after the change of the regime, Hungarian scholars' key research question addressed the opposite issue: why Hungarian SMEs perform poorly; why they are unable and/or unwilling to grow? 
Major [2003; 2008] showed that despite substantial government support, Hungarian SMEs produce far less than their input endowments would suggest. Small firms' failure to graduate into medium-sized ones is explained by technical and allocative inefficiencies and cultural factors, such as taking profit out of (rather than reinvesting into) their small, family-managed ventures.

In an international comparison measured by the Global Entrepreneurship and Development Index [GEDI, Ács et al., 2015], entrepreneurship in Hungary scores rather weakly, especially in terms of entrepreneurs' engagement in process and product innovation and the availability of risk capital [Szerb et al., 2012]. The persistence of Hungarian SMEs' weak growth potential (and weak commitment to grow) is mirrored by the low value of the GEDI pillar that quantifies nascent and start-up business owners' growth ambitions. Szerb et al. [2012] found that of the three GEDI sub-indices (Entrepreneurial Attitudes, Entrepreneurial Activities and Entrepreneurial Aspirations), Hungary receives the lowest scores for Entrepreneurial Aspirations. ${ }^{2}$

The value of this sub-index is far below those of Hungary's CEE counterparts and those of advanced economies.

By the end of the $2000 \mathrm{~s}$, the traditional focus of Hungarian SME-researchers on the deficiencies of entrepreneurial performance became more diversified: Hungarian scholars have also identified the HGF segment within the Hungarian business ecosystem and begun investigating HGFs' attributes [Békés-Muraközy, 2012; Papanek, 2010].

In line with the literature, Hungarian case-study-based investigations found a strong correlation between high growth and innovativeness, high growth and internationalization, and high growth and venture financing [Szerb et al. 2012]. The main barriers to the further growth of Hungarian HGFs are also similar to those faced by their advanced economy peers: access to financing and an adequately skilled workforce [Csapó, 2011].

\section{Research Method and Sample}

Since our research questions address complex, multifaceted, and dynamically changing issues that are contextually situated, exploratory research and comparative, multiple-case analysis aiming at inductive theory building seemed an optimal approach [Eisenhardt, 1989; Yin, 2003].

We used both primary and secondary data sources. Primary data collection involved face-to-face or telephone interviews with founders and/or managers of the sampled companies. Our interviews were guided by a semi-structured interview protocol with open-ended questions about the problems that emerged in the course of growth periods and reactions to them.

Given the relatively low precision of qualitative methods and impossibility of following strict replication logic [Yin, 2003], several other actions were taken to ensure reliability 
and validity (above and beyond the creation of an interview protocol to ensure systematic data collection). First, we verified our findings by adopting multiple perspectives, i.e. by triangulating case study information with information from secondary data sources, such as newspaper articles describing the given firm's achievements, information brochures, business reports and publicly available balance sheet and profit and loss statements. Second, draft reports were sent back to the interviewed managers for approval and feedback. Third, wherever possible, we prepared interviews with more than one representative of the firms sampled, or employed a 'repeated interview' technique to clarify selected details.

Having created a database of encountered problems, proposed responses, and changes implemented at the surveyed firms, we first filtered the results with regard to Winter's [2003] thesis that DC are not about ad hoc problem solving: they are repeatable (persistent) capabilities to adjust to changes in the external environment through changes in the firm's resource base. Next, we analyzed the filtered stock of problems and solutions to identify commonalities. Dominant parts of the responses were either related to the development or acquisition of additional organizational resources and competences or to the reconfiguration of the organizational structure. ${ }^{3}$

TABLE 1. Data on the surveyed companies

\begin{tabular}{|c|c|l|c|c|c|c|c|}
\hline & Foundation & \multicolumn{1}{|c|}{ Product } & $\begin{array}{c}\text { Number of } \\
\text { employes } \\
(2014)\end{array}$ & $\begin{array}{c}\text { Sales } \\
2014 \\
(€ \mathrm{~m})\end{array}$ & $\begin{array}{c}\text { Sales growth } \\
\%, \\
(\text { from - to })\end{array}$ & $\begin{array}{c}\text { Continuous } \\
\text { growth }\end{array}$ & $\begin{array}{c}\text { Managed } \\
\text { by owner } \\
\text { \& founder }\end{array}$ \\
\hline A & 2004 & $\begin{array}{l}\text { Customized software, } \\
\text { contract R\&D }\end{array}$ & 30 & 0.7 & $\begin{array}{c}540 \\
(2009-2013)\end{array}$ & no & yes \\
\hline B & 2008 & $\begin{array}{l}\text { Renewable energy- } \\
\text { based heating and air- } \\
\text { conditioning solutions }\end{array}$ & 4 & 1.85 & $\begin{array}{c}415 \\
(2011-2014)\end{array}$ & no & no \\
\hline C & 2005 & $\begin{array}{l}\text { GPS tracking system } \\
\text { solutions }\end{array}$ & 63 & 3.2 & $\begin{array}{c}438 \\
(2009-2014)\end{array}$ & yes & yes \\
\hline D & 2007 & $\begin{array}{l}\text { Online accommodation } \\
\text { brokerage }\end{array}$ & 97 & 4.47 & $\begin{array}{c}1325 \\
(2011-2014)\end{array}$ & yes & no \\
\hline E & 2005 & $\begin{array}{l}\text { Time-lapse embryo } \\
\text { monitoring system }\end{array}$ & 38 & 2.87 & $\begin{array}{c}430 \\
(2011-2014)\end{array}$ & yes & no \\
\hline
\end{tabular}

* = continuous growth since inception

S o u r c e: author's compilation based on corporate data.

Our sample is composed of five companies, selected on the basis of three criteria. First, they operate in technology-intensive industries and their products and/or services are based on the innovative idea(s)/solution(s) of the founder (they should be examples of technology-based entrepreneurship). Second, they are indigenously owned, and established by individual entrepreneurs. Nevertheless, if a surveyed company complied with all 
our selection criteria but was recently acquired by a foreign investor, this was considered an asset that adds new insights. Third, they exhibit high (turnover) growth periods of at least $20 \%$ annually, for at least three years.

Drawing on the author's database of newspaper articles on successful Hungarian SMEs, a theoretical sampling procedure was adopted [Eisenhardt, 1989]: we selected cases that were considered revelatory and particularly suitable for offering theoretical insights. As we were interested in identifying commonalities behind idiosyncratic corporate histories, we included companies of different sizes and sectors. Table 1 provides a summary description of the sample companies.

\section{Research Results}

In line with the relevant literature concerning the homogeneity of challenges faced by HGFs in high growth periods [Chan et al., 2006] the problems mentioned during the interviews were more or less similar across firms. They included problems associated with increasing size and organizational complexity (leadership problems; stresses and strains stemming from deficiencies in the internal information flow), and traditional managerial challenges associated with expansion (reputation development, international expansion and market knowledge building, recruitment and retention, financing).

This section will review the proposed organizational solutions, i.e. organizational changes implemented by the surveyed firms to resolve the emerging problems. First, the application of textbook-type best practice organizational solutions (to growth related problems) is presented. In the next two subsections, we describe more fundamental organizational transformations implemented by the surveyed firms.

\section{Textbook-Type Best Practice Organizational Solutions to Growth Related Problems}

Successful entrepreneurs in technology-oriented sectors can seize the identified business opportunities if they are able to combine two activities: technology development and business development. A common mistakes entrepreneurs in technology-oriented sectors commit is devoting too much attention to technology development at the expense of business development. The surveyed HGFs managed to avoid this first trap along their business development trajectory: they exhibited outstanding growth performance because in addition to strong technological capabilities and entrepreneurial orientation [LumpkinDess, 1996], they possess extraordinary business development and marketing capabilities. 
Sustaining growth and managing a growing organization, however, requires more than a visionary entrepreneur who can seize the identified business opportunities. The first common problem mentioned by practically all managers interviewed is that organizational growth triggers a multiplication of tasks that are different from the original two core activities.

New capabilities were deemed necessary, such as overseeing increasingly complex structures and interactions; employee selection and team building; organization of efficient internal communication (and management of communication problems); management and control of transaction costs that tend to increase rapidly along with growth, and so forth.

Tensions emerged not only because of founders-executives' declining oversight and the excessive time required to implement, coordinate and control rapidly multiplying support tasks. Another cause of recurrent conflicts (as explained by the founders interviewed) was that above a certain threshold turnover, the low level of division of labor (employee versatility) that initially worked well frequently provoked hard-to-manage problems, as illustrated by the following interview excerpt.

"We realized that our firm resembles a small pirate ship: everyone in the crew can equally be engaged in navigation, maintenance and battle, and everyone can decide where to go next. This manner of operation was self-evident when we were three or four, but over time clashes in authority and problems stemming from lack of information what our colleagues have negotiated upon with the new customers have become increasingly frequent."

The surveyed firms' responses to these problems, though idiosyncratic in their details, can nevertheless be easily classified as professionalization of leadership and reconfiguration of the organizational structure. The actions implemented included

- recruitment of new managers and the building of a management team;

- increasing internal functional specialization, and the creation of functional departments;

- authority decentralization: founders' delegation of responsibility for operational tasks to lower levels, in order to become more focused on strategic functions;

- founders' giving up the managing director's position and hiring a professional CEO;

These actions provided a solution to the founder-executive's diminishing oversight of increasingly complex operations.

The surveyed cases featured non-negligible differences with respect to some details. Transferring leadership tasks to a professional manager was in one case considered a relief by the scientist and founder of the company: in this vein he could return to scientific research and delegate management tasks to someone experienced in coordination, control, strategy building and implementation.

In another case, the professionalization of leadership was triggered by a serious illness that forced the founder to take a step backwards. The founder's son, who had been working with his father since the firm's inception as chief technical officer and developer (but was equally involved in managing everyday operations), became the chief strategy officer. The 
family owners gradually hired professional managers for an increasing number of business functions, e.g. for marketing and customer relationship management.

In a third case the need to involve a venture capital investor prompted the hiring of a professional manager who created an organizational structure acceptable for venture capital investors. The new managing director clearly delineated internal responsibilities and created a transparent organization with a clear-cut strategy and well-defined responsibilities.

In another case the partial takeover of the firm led to transforming the organization: The new owner appointed a managing director who determined the development trajectory, and identified the functional areas that are bound to become the engines of growth: a marketing-intensive growth period first, and a product development-intensive growth period thereafter. Strategy implementation involved substantial job creation, which triggered an increase in task specialization and hierarchical levels.

Besides firm-specific details, the key commonality can be summarized as follows. The problems that emerged in the course of each surveyed firm's growth processes required a reconfiguration of the framework that shapes the firm's work. This reconfiguration involved professionalization of the leadership and decentralization of planning, operating and control functions (together with the decentralization of decision-making). By this process the organizations became increasingly formalized: internal specialization increased, employee and task versatility receded, and informal, functionally integrated organizations evolved into functionally specialized, formally organized entities.

Note that reconfiguring the organizational structure involved some resource shedding. Although a founder's relinquishment of management control to professional managers improves an HGF's further growth or, at least, ensure the sustainability of past achievements [Abebe-Alvarado, 2013; Boeker-Karichalil, 2002; Wasserman, 2008], a founder's 'stepping back' may have deprived some organizations of the ambition and commitment that characterized that founder. The founder's drive, described by McGrath-MacMillan [2000] as the entrepreneur's capability to engage the energy of all who work with him, was replaced by the professionalism of the newly hired CEO and the formal routines of the human resources management processes.

\section{Fundamental Organizational Changes}

In some cases the organizational transformation that accompanied the surveyed companies' growth has transcended a simple 'definition and delineation of responsibilities' and professionalization of leadership. Growth triggered (or was accompanied by) more fundamental organizational changes.

Organizational changes at (C) took a new turn following their decision to transform the applied business model. Recognizing that services ensure a continuous and predictable 
flow of income, ${ }^{4}(\mathrm{C})$ redefined its business model from one of selling and deploying devices (GPS tracking systems) into providing GPS-based services (route registry, theft protection; tracking, temperature monitoring). In terms of strategy, this implied an increased focus on customer retention through additional and improved services. Instead of seeking new customers, selling upgraded services to existing customers and improving customer loyalty became the primary objectives. ${ }^{5}$ Changes in strategy entailed a movement towards a customer-focused organizational structure. Key account manager posts were created and the corporate organization was redesigned around them. Consequently, the previously well-delineated functional boundaries (that had been defined as an outcome of C's adjustment to growth related problems, such as task multiplication and the founder-executive's declining overview) have become more permeable again, as a result of increased reliance on cross-functional teams.

A's case exemplifies a radical organizational innovation. (A) developed an organizational framework that enables continuous change: a par excellence manifestation of DC!

Beyond a certain threshold of size and degree of product mix diversification, (A) decided to create separate legal entities for each new product that had already proved its viability. The goal of the organizational transformation was to structure individual products or product families as independent profit centers. Meanwhile the interviewed (original) company transformed itself into a holding company that provided back office services, financing, and marketing services to the individual portfolio companies. The holding company retained responsibility for new product development and delegated incremental development tasks to the newly created companies. This obviously implied the delegation of a number of responsibilities to the managing directors of individual product lines. Consequently, authority became decentralized: the managing directors of the portfolio companies controlled the everyday operational affairs related to their product lines. The founder of the original company has become the CEO of the holding company. He coordinated the portfolio companies and was responsible for business development, financing, and the coordination of new product development.

In other cases growth related organizational transformation had an impact on a given firm's boundaries.

Rapid growth at (E) prompted a decision to insource tasks that had previously been carried out by external contractors, such as hardware and software development and component development (manufacturing tasks, however, remained outsourced). "Bringing external knowledge in-house reduces risks and ensures that key competences develop in line with growth," the interviewed manager explained.

Conversely, (B) opted to manage growth through outsourcing (indirect job creation, instead of offering full-time employment). It decided to outsource support functions, such as accounting or legal services, and work together with business partners and subcontractors that undertake the construction, related administrative work, and maintenance and control of B's running systems. Furthermore, (B) established a network of (freelance) 
engineers working on a contractual basis. B's solution is subject to continuous adaptive and incremental innovations. The design of new projects and project proposals also requires substantial engineering work. Accordingly, the executive manager currently works together with and coordinates the development activities of 15 to 20 engineers. Some of them have become strategic partners who have worked for (B) as subcontractors for several years now. Altogether, irrespective of B's rapid revenue growth (sales increased more than fourfold between 2011 and 2014) there are only four employees.

A key commonality of the idiosyncratic developments listed above was that each surveyed firm adjusted its operational mode and business models during the business development process. On one hand, these corporate initiatives had organizational implications. On the other hand, the surveyed HGFs reconfigured the organizational structure to facilitate further adjustments to changes in the internal and external environment.

Beyond structural organizational innovations, the surveyed firms initiated and implemented several procedural organizational innovations ${ }^{6}$ (POI) to mitigate the tensions arising from the growing complexity of their operations.

One of the most common POI was the purchase or in-house development of corporate information systems that contributed to increasing organizational effectiveness and transactional transparency. Moreover, as the manager of (C) explained, their deployment of a SAP system proved to be a means of reputation building: corporate customers recognized the value associated with this specific type of intangible investment and considered it tangible evidence of a long-term strategy.

A further common POI was the surveyed firms' formalization of rules and procedures. This is illustrated by the accounts of three informants.

"From time to time similar problems emerged, and we started to ponder again and again what kind of decision to take. For example, there was no agreement on the extent of discounts that can be offered to selected customers. One of our sales employees tended to offer larger discounts than the others, and customers who did not receive equal benefits got upset. So we immediately decided to establish consistency by specifying every possible circumstance under which discounts can be offered."

"We suddenly realized that the development process of new products takes much more time than previously. When asked about the reason, the software development staffexplained that they keep receiving urgent tasks from the marketing and customer relationship management employees: they have to fix a number of problems signaled by the customers. It soon turned out that customers have in reality asked for the development of additional functionalities, but they communicated their requirements as if there were problems with the existing software. Developers spent a couple of hours/days to implement the emerging requirements and meanwhile they stopped working on the development tasks assigned to them. We decided to 'specify the hierarchy', and stipulated that it is only the top management who can assign new tasks to software developers. Problems and additional wishes signaled to the customer 
relationship management staff have to be compiled and they undergo a review and selection process. Furthermore, we stipulated that every employee has to keep a work diary."

"We felt increasing pressure to write down rules for everything. Nevertheless, we tried to leave sufficient scope for spontaneity and preserve as much of our organizational tradition as possible. At the same time it was necessary to formally stipulate behavioral regularities in the case of blue collar workers: we have even prepared a manual for them that specifies all the work processes to be implemented and determines their sequencing as well."

These firm-specific details highlight that DC are indispensable in deciding what to formalize. Formal rules abate intra-organizational conflicts but tend to jeopardize flexibility. DC are manifest in management's ability to assess the constraining and the enabling effects of each action aimed at the formalization of work processes.

Another POI adopted sooner or later by every firm in the sample was the development of strategic plans. Although the founders had a clear vision about how to proceed with and carry out business development, they did not start with writing formal business plans. With the upscaling of operations however, the need to develop a formal strategy became increasingly pressing. In some cases, formal plans determining a firm's mission, detailing short and medium-term business development trajectory, stipulating objectives, the describing strategy implementation and the related responsibilities became a necessary condition of attracting external investors. Others prepared partial strategy papers that either addressed one single business function, e.g., preparation of a medium term marketing strategy; and setting up of a technology roadmap that directed development activities or determined the tasks related to one specific strategic action, such as expanding into a new market.

As the narratives of the interviewed executives made it clear, strategic planning was initially an ad hoc exercise that gradually became a continuous activity. Initial plans were refined and expanded to cover additional business functions. Furthermore, in two cases the founder/CEO pointed out that management regularly assesses the validity of the plans, modifies the objectives as necessary and sets up new targets: these activities, again, are par excellence manifestations of DC. Strategic planning achieved a qualitatively higher development level in one case, where the new strategy papers started to incorporate performance evaluation criteria as well.

\section{Inter-Organizational Innovations}

In a typology of organizational innovations developed by Armbruster et al. [2008], organizational innovations are differentiated along an intra-organizational and inter-organizational dimension. The foregoing discussion reviewed examples of intra-organizational 
transformation, implemented in reaction to emerging growth-specific problems. Ambruster et al. defined inter-organizational innovations as the development of "new organizational structures or procedures beyond a company's boundaries. These comprise new organizational structures in an organization's environment, such as R\&D cooperation with customers, just-in-time processes with suppliers or customers or supply chain management practices with suppliers" [p. 646].

Our interviews have uncovered a number of inter-organizational innovations implemented by the surveyed firms to resolve emerging managerial challenges perceived as obstacles to sustained competitiveness.

As the quotations below make it clear, the founders and managers of the surveyed HGFs encountered a number of traditional business development challenges - some of which could be handled by either building strategic alliances and/or implementing other inter-organizational innovations that increase the given firms' outreach beyond corporate boundaries - or by attracting an external investor.

"We have come to realize that we are not the best in commercializing every product we develop." "To gain the contract of a high-capital-expenditure project, it is indispensable to establish credibility and build international reputation. Even if our solution is innovative and promises rapid return, it is tremendously difficult for a small Hungarian firm, to achieve trust and gain recognition in a competitive landscape dominated by large international actors in this industry."

"It was not the well-capitalized status of our new owner that was the most important for us, rather, that this firm has been present in the global market for 25 years: it has a well-established brand name and access to key users and researchers all over the world. Through its global technical support organization it is in close contact with the clinics where the products are used: for a biotechnology firm nothing can be more valuable."

The inter-organizational innovations the managers interviewed mentioned effectively address a number of traditional managerial challenges associated with expansion.

(B) created strategic alliances with several key suppliers. ${ }^{7}$ One of its suppliers, a global manufacturer of air conditioning systems, recommends B's renewable energy system solution to its own clients (who are property developers). In return, B integrates the supplier's air conditioning system (and some other components) into its solution. In a similar vein, B established collaborative partnerships with other part and sub-system suppliers of its complex system.

(E) entered into strategic alliances with selected users of its technology (clinics). Users evaluate the technology and provide regular feedback on their experiences, giving the firm real world inputs for further technology improvement.

(D)'s expansion was boosted by a strategic alliance with a competitor. To increase and diversify its supply, (D) integrated the supply of a German online accommodation brokerage 
firm into its own. At the same time it also increased the organization's outreach beyond corporate boundaries by strategic alliances with online news portals, and by building up a network of marketing and sales agents in a variety of countries (similarly to B and C).

Similarly to the aforementioned examples of inter-organizational innovations in the form of collaborative partnerships to access complementary assets, attracting an external investor also proved to be a means of mobilizing external resources. In two cases, the required volume of complementary financial and intangible resources increased so swiftly during the expansion phase that the takeover of the firm by an external investor proved to be inevitable. In both cases, the acquisition of the HGF by an external investor has reinforced the above-reviewed organizational transformations.

\section{Discussion and Conclusions}

The key argument that was illustrated with case studies in this paper was that behind idiosyncratic details, successful HGFs are quite similar in terms of a) the factors that account for their sustained competitiveness; and b) the challenges they face in the course of rapid growth periods. HGF founders and executives can effectively manage the entrepreneurial process and survive rapid growth periods through developing and leveraging dynamic capabilities. They continually revise and renew both their managerial practices and the configuration of the organization.

Intra- and/or inter-organizational changes are implemented in response to the extension and the growing complexity of resources. In this vein, new organizational solutions facilitate the rational use of an increased and/or diversified resource base. Moreover, changes in strategy triggered (or were accompanied by) changes in the organizational structure. Organizational innovations were sometimes also introduced in anticipation of forthcoming changes in the business environment. In summary, organizational changes support the effective implementation of changes in strategy, driven by a changing environment and a firm's growing resource base. ${ }^{8}$

The objective of this paper was to explore how DC become manifest while HGFs strive to meet the managerial challenges posed by rapid growth. We delved into the micro mechanisms of HGFs' leveraging their DC by scrutinizing the organizational solutions they implemented in response to problems. We found more or less similar organizational responses to growth-specific problems across the sample.

In response to internal and external environment changes due to growth, the surveyed firms developed new operational and organizational routines and built networks to access and integrate additional resources. The recurrent growth-related reconfiguration of the organizational structure and the introduction of various organizational innovations are the result of systematically developed DC and of non-abating organizational learning. 
Certain limitations of this research are, however, worth noting. The applicability of our findings may be limited by the type of firms investigated here. As indicated previously, sample firms illustrate the experiences of a well-delineated subset of HGFs: technology-oriented, relatively young SMEs. Moreover, the small sample size also constrains generalization. Further studies may integrate perspectives that are currently missing because of the small sample size, for example the impact of innovation collaborations that are also primary examples of inter-organizational innovations. ${ }^{9}$

Furthermore, our focus was limited to organizational responses to emerging growth-specific problems, which is one element, or rather one manifestation of the multidimensional and complex processes DC are leveraged while reconfiguring internal and integrating external resources. Further empirical research is necessary to examine HGFs' responses to growth-specific problems, and to identify and analyze additional commonalities.

\section{Acknowledgement}

Research for this paper was supported by the Hungarian National Scientific Research Fund (OTKA K109294, coordinator: Magdolna Sass) and by the Hungarian Academy of Sciences (Hungary-Poland bilateral international research project, coordinator: Miklós Szanyi).

\section{Notes}

1 Author's e-mail address: aszalave@gmail.com

2 "Entrepreneurial Aspiration refers to the distinctive, qualitative, market expanding, wealth enhancing entrepreneurial activity such as the newness of the product and technology used by a venture, internationalization, high growth ambitions as well as the availability of risk capital." [Szerb et al., 2012, p. 18; emphasis added].

3 Another type of responses targeted the development and accumulation of complementary assets. The related strategic actions will be analyzed in a companion paper.

4 C's GPS devices are currently installed in more than 20,000 cars.

5 Needless to emphasise that the expansion of the customer base remained an important business objective also after the redefinition of C's customer value proposition..

6 Armbruster et al. [2008] classify organizational innovation in two categories: structural organizational innovation and procedural organizational innovation. The former refers to changes in the divisional structure of functions and/or in the number of hierarchical levels. Structural organizational innovation may also affect the firm's boundaries (offshoring, or reshoring, in-or outsourcing, relocation, etc.). Procedural organizational innovation affects the routines, processes and operations of a company.

7 In B's case, increasing the organization's outreach and developing strategic partnerships was driven also by industry-specific features. Local building regulations often stipulate that the design of the renewable energy system that is integrated in residential or commercial buildings is carried out by a locally 
approved and certified specialist. Moreover, construction works are subject to a number of regulations, and individual phases of project implementation require permissions and statutory approvals issued by local authorities. Consequently, collaboration with principal contractors, local partners and subcontractors is self-evident.

8 The author is indebted to the anonymous reviewer of her paper for raising the points described in this paragraph.

9 Although interviewees have been explicitly asked about their experiences with open innovation, sample companies have not engaged in R\&D collaboration with external stakeholders yet. This finding may be explained with small sample size and with the characteristics of small, technology-oriented startups to bring (and keep) key competences in-house.

\section{References}

Abebe, M., Alvarado, A.D. (2013), Founder-CEO status and firm performance: an exploratory study of alternative perspectives, Journal of Strategy and Management, Vol. 6, No. 4, pp. 343-357.

Ács, Z.J. (2011), High-impact firms: gazelles revisited, in: M. Fritsch (ed.), Handbook of research on entrepreneurship and regional development: National and regional perspectives, Edward Elgar, Cheltenham, pp. 133-174.

Ács, Z.J., Szerb, L., Autio, E. (2015), Global Entrepreneurship and Development Index 2014, Springer Briefs in Economics, Springer, Heidelberg.

Agarwal, R., Helfat, C.E. (2009), Strategic renewal of organizations, Organization Science, Vol. 20, No. 2, pp. 281-293.

Armbruster, H., Bikfalvi, A., Kinkel, S., Lay, G. (2008), Organizational innovation: The challenge of measuring non-technical innovation in large-scale surveys, Technovation, Vol. 28, No. 10, pp. 644-657.

Békés, G., Muraközy, B. (2012), Magyar gazellák: gyorsnövekedésűvállalatokjellemzőiéskialakulásukelemzése Magyarországon, [Hungarian gazelles: what makes a high-growth firm in Hungary?], Közgazdaság Szemle, Vol. 59, No. 3, pp. 233-262.

Barbero, J.L., Casillas, J.C., Feldman, H.D. (2011), Managerial capabilities and paths to growth as determinants of high-growth small and medium-sized enterprises, International Small Business Journal, Vol. 29, No. 6, pp. 671-694.

Birch, D. (1979), The Job Generation Process, Cambridge, MA, MIT Program on Neighborhood and Regional Change, Unpublished report U.S. Department of Commerce.

Birch, D.L., Medoff, J. (1994), Gazelles, in: L.C. Solmon, A.R. Levenson, (eds.), Labor markets, employment policy and job creation, Westview, Boulder, Co, pp. 159-167.

Boeker, W., Karichalil, R. (2002), Entrepreneurial transitions: Factors influencing founder departure, Academy of Management Journal, Vol. 45, No. 4, pp. 818-826.

Chan, Y.E., Bhargava, N., Street, C.T. (2006), Having Arrived: The Homogeneity of High-Growth Small Firms, Journal of Small Business Management, Vol. 44, No. 3, pp. 426-440.

Coad, A., Daunfeldt, S.O., Hölzl, W., Johansson, D., Nightingale, P. (2014), High-growth firms: introduction to the special section, Industrial and Corporate Change, Vol. 23, No. 1, pp. 91-112.

Colombelli, A., Krafft, J., Quatraro, F. (2014), High-growth firms and technological knowledge: do gazelles follow exploration or exploitation strategies?, Industrial and Corporate Change, Vol. 23, No. 1, pp. 261-291.

Csapó, K. (2011), The Characteristics and Development Possibilities of Fast-Growing SMEs in Hungary, ERENET Profile, Vol. 6, No. 3, pp. 16-27.

Davidsson, P. (1991), Continued entrepreneurship: Ability, need, and opportunity as determinants of small firm growth, Journal of Business Venturing, Vol. 6, No. 6, pp. 405-429. 
Deligianni, I., Voudouris, I., Lioukas, S. (2014), Growth paths of small technology firms: The effects of different knowledge types over time, Journal of World Business, in Press, doi:10.1016/j.jwb, (accessed: August 6, 2014).

Delmar, F., Davidsson, P., Gartner, W.B. (2003), Arriving at the high-growth firm, Journal of Business Venturing, Vol. 18, No. 2, pp. 189-216.

Eisenhardt, K.M. (1989), Building theories from case study research, Academy of Management Review, Vol. 14, No. 4, pp. 532-550.

Eisenhardt, K.M., Graebner, M.E. (2007), Theory building from cases: Opportunities and challenges, Academy of Management Journal, Vol. 50, No. 1, pp. 25-32.

Eisenhardt, K.M., Martin, J.A. (2000), Dynamic capabilities: What are they?, Strategic Management Journal, Vol. 21, No. 1, pp. 1105-1121.

Foss, N.J., Laursen, K., Pedersen, T. (2011), Linking customer interaction and innovation: The mediating role of new organizational practices, Organization Science, Vol. 22, No. 4, pp. 980-999.

Hambrick, D.C., Crozier, L.M. (1986), Stumblers and stars in the management of rapid growth, Journal of Business Venturing, Vol. 1, No. 1, pp. 31-45.

Henrekson, M., Johansson, D. (2010), Gazelles as job creators: a survey and interpretation of the evidence, Small Business Economics, Vol. 35, No. 2, pp. 227-244.

Hsu, L.C., Wang, C.H. (2012), Clarifying the effect of intellectual capital on performance: the mediating role of dynamic capability, British Journal of Management, Vol. 23, No. 2, pp. 179-205.

Lumpkin, G.T., Dess, G.G. (1996), Clarifying the entrepreneurial orientation construct and linking it to performance, Academy of Management Review, Vol. 21, No. 1, pp. 135-172.

Major, I. (2003), What Makes Hungarian SMEs Perform Poorly?, Acta Oeconomica, Vol. 53, No. 2, pp. 109-143.

Major, I. (2008), Technical efficiency, allocative efficiency and profitability in Hungarian small and medium-sized enterprises: a model with frontier functions, Europe-Asia Studies, Vol. 60, No. 8, pp. 1371-1396.

McGrath, R.G., MacMillan, I. (2000), The EntrepreneurialMindset, Harvard Business School Press, Boston.

Mueller, S., Volery, T., Von Siemens, B. (2012), What Do Entrepreneurs Actually Do? An Observational Study of Entrepreneurs' Everyday Behavior in the Start-Up and Growth Stages, Entrepreneurship Theory and Practice, Vol. 36, No. 5, pp. 995-1017.

Papanek, G. (2010), A gyorsannövekvőmagyarkis- ésközépvállallatok a gazdaságmotorjai, [High-growth Hungarian SMEs are the engines of the economy], Közgazdasági Szemle, Vol. 57, No. 4, pp. 357-370.

Parker, S.C., Storey, D.J., Van Witteloostuijn, A. (2010), What happens to gazelles? The importance of dynamic management strategy, Small Business Economics, Vol. 35, No. 2, pp. 203-226.

Sadler - Smith, E., Hampson, Y., Chaston, I., Badger, B. (2003), Managerial behavior, entrepreneurial style, and small firm performance, Journal of Small Business Management, Vol. 41, No. 1, pp. 47-67.

Smallbone, D., Leig, R., North, D. (1995), The characteristics and strategies of high growth SMEs, International Journal of Entrepreneurial Behaviore Research, Vol. 1, No. 3, pp. 44-62.

St-Jean, E., Julien, P.A., Audet, J. (2008), Factors associated with growth changes in "gazelles", Journal of Enterprising Culture, Vol. 16, No. 2, pp. 161-188.

Storey, D.J. (1994), Understanding the small business sector, Routledge, London.

Szerb, L., Aidis, R., Ács, Z.J. (2012), Entrepreneurship in Hungary in the 2006-2010 time period., Global Entrepreneurship Monitor Hungary Report, available at: http://new.gemconsortium.org/assets/uploads/1340894072GEM_ Hungary_Report_2006_2010.pdf

Teece, D.J. (2007), Explicating dynamic capabilities: the nature and microfoundations of (sustainable) enterprise performance, Strategic Management Journal, Vol. 28, No. 13, pp. 1319-1350. 
Teece, D.J. (1986), Profiting from technological innovation: Implications for integration, collaboration, licensing and public policy, Research Policy, Vol. 15, No. 6, pp. 285-305.

Teece, D.J., Pisano, G., Shuen, A. (1997), Dynamic capabilities and strategic management, Strategic Management Journal, Vol. 18, No. 7, pp. 509-533.

Terjesen, S., Hessels, J., Li, D. (2013), Comparative International Entrepreneurship, A Review and Research Agenda, Journal of Management, DOI: 10.1177/0149206313486259

Wasserman, N. (2008), The founder's dilemma, Harvard Business Review, Vol. 86, No. 2, pp. 102-109.

Wennberg, K. (2013), Managing High-Growth Firms: A literature review, available at: https://search.oecd. org/cfe/leed/Wennberg_Managing\%20a\%20HGF.pdf

Winter, S.G. (2003), Understanding dynamic capabilities, Strategic Management Journal, 24, No. 10, pp. 991-995. Yin, R.K. (2003), Case study research: Design and methods, Sage publications, Thousand Oaks, CA.

Zahra, S.A., Sapienza, H.J., Davidsson, P. (2006), Entrepreneurship and dynamic capabilities: a review, model and research agenda, Journal of Management Studies, Vol. 43, No. 4, pp. 917-955.

Zollo, M., Winter, S.G. (2002), Deliberate learning and the evolution of dynamic capabilities, Organization Science, Vol. 13, No. 3, pp. 339-351. 